\title{
EXTRACORPOREAL MEMBRANE OXYGENATION FOR STATUS ASTHMATICUS: A CASE REPORT ECMO FOR STATUS ASTHMATICUS
}

\author{
H. LAMBA, Y. ELGUDIN, S. DEO, B. MEDALION, B. SAREYYUPOGLU, A. MARKOWITZ, S. PARK \\ University Hospitals Cleveland Medical Center Harrington Heart and Vascular Institute, Cleveland, USA
}

\begin{abstract}
Technological advances in extracorporeal membrane oxygenation and emerging evidence that it improves survival in adults with reversible respiratory failure compared to conventional ventilation has lead to increased utilization of extracorporeal membrane oxygenation in adults, usually in the context of acute respiratory distress syndrome. Refractory status asthmaticus is an uncommon indication for extra-
\end{abstract}

corporeal membrane oxygenation. We present a case of near fatal respiratory failure and hypercapnia in a 48 -year-old male in status asthmaticus not responsive to optimal ventilatory treatment. The use of veno-venous extracorporeal membrane oxygenation resulted in full recovery with return of normal respiratory function within nine days.

Keywords: acute respiratory failure, bronchial asthma, extracorporeal membrane oxygenation.

For citation: Lamba H.K., Elgudin Y., Deo S., Medalion B., SareyyupogluB., Markowitz A., ParkS. Extracorporeal membrane oxygenation for status asthmaticus: a case report ECMO for status asthmaticus. Complex Issues of Cardiovascular Diseases. 2017;6(4): 146-147 DOI:10.17802/2306-1278-2017-6-4-146-147

\section{Abbreviations:}

ECMO - extracorporeal membrane oxygenation

PEEP- positive end-expiratory pressure

\section{Introduction}

Status asthmaticus is an acute exacerbation of asthma that is unresponsive to repeated courses of beta-agonist therapy and is associated with signs or symptoms of potential respiratory failure. Mechanical ventilation for respiratory failure is currently the treatment of choice in severe cases of asthma, but is associated with increased in-hospital mortality compared with patients who do not require mechanical ventilation [1]. Ventilator strategies have been adopted to minimize complications such as barotrauma, dynamic hyperinflation and auto-positive end expiratory pressure but the new strategies have not eliminated these complications. In patients with ventilation-refractory hypercapnia and respiratory acidosis, extracorporeal membrane oxygenation (ECMO) may be an alternative ventilation strategy. Here we present our experience with veno-venous (V-V) ECMO for the treatment of hypercapneic respiratory failure in an adult male with severe refractory status asthmaticus.

\section{Case Report}

A 48-year-old man with past medical history significant for Human Immunodeficiency Virus (CD4 266 and viral load 215) presented to the ED with increasing dyspnea over two days. He had a known history of severe persistent asthma with frequent exacerbations including a recent admission requiring mechanical ventilation for 8 days. He reported compliance with his regular antiviral and asthma medications.

\section{$\mathrm{RR}$-respiratory rate \\ TV- tidal volume \\ $\mathrm{V}-\mathrm{V}$ - veno-venous}

Upon presentation he was dyspneic and wheezing and tachycardic with heart rate of 104/min. He was not hypotensive or tachypneic and had arterial oxygenation of $98 \%$ on room air. Chest x-ray demonstrated hyperinflation. He was initially treated with oxygen therapy via 2 liters nasal cannula, nebulized ipratropium bromide and albuterol, methylprednisolone $125 \mathrm{mg}$, magnesium sulfate $2 \mathrm{~g}$, ceftriaxone $1 \mathrm{~g}$ and azithromycin $500 \mathrm{mg}$. He was admitted to the hospital and maintained on nebulized ipratropium and albuterol q4 hours. On morning rounds patient was tachypneic with respiratory rate of $33 / \mathrm{min}$ and diffuse wheezing on exam with minimal air movement. His ipratropium bromide and albuterol treatments were increased to q2 hours. His arterial oxygen saturation was 97\% on $2 \mathrm{~L}$ nasal cannula but repeat arterial blood gas demonstrated carbon dioxide retention: $\mathrm{pH} 7.31 \mathrm{pCO}_{2} 45 \mathrm{mmHg}, \mathrm{pO}_{2} 84$ $\mathrm{mmHg}, \mathrm{HCO}_{3}-22.7 \mathrm{mmol} / \mathrm{L}$.

He was transferred to the MICU where he developed marked respiratory distress with accessory muscle use despite use of $30 \%$ non-rebreather mask. He received another dose of magnesium sulfate $2 \mathrm{mg}$ and was started on heliox gas. He continued to maintain oxygen saturation over $90 \%$ but remained in respiratory distress with significant work of breathing. Oxygen therapy with non-invasive ventilator support via bipap at an inspiratory pressure of 15 and expiratory pressure of 4 was initiated. However, he remained tachypneic, became increasingly fatigued and was found to have worsening respiratory acidosis: $\mathrm{pH}$ $7.25, \mathrm{pCO}_{2} 54 \mathrm{mmHg}, \mathrm{pO}_{2} 76 \mathrm{mmHg}, \mathrm{HCO}_{3}-23.7 \mathrm{mmol} / \mathrm{L}$. 
The patient was intubated and started on assist control mode ventilation, with respiratory rate (RR) of 20 , tidal volume (TV) of $460 \mathrm{ml}, \mathrm{FiO}_{2} 40 \%$, I:E ratio of $1: 2.5$, and positive end-expiratory pressure (PEEP) of $0 \mathrm{~cm} \mathrm{H}_{2} \mathrm{O}$. Adjunctive treatment with continuous nebulized ipratropium bromide and albuterol, aminophylline (500 mg), corticosteroid (60 mg q $6 \mathrm{hr}$ ), and magnesium sulfate ( $2 \mathrm{mg} \mathrm{q}$ $6 \mathrm{hr}$ ) were continued. Additionally, treatment with continuous ketamine $(1 \mathrm{mg} / \mathrm{kg} / \mathrm{hr}$ ) and the inhalation anesthetic agent isoflurane was initiated. His condition continued to deteriorate with worsening hypercapnia: $\mathrm{pH} 7.15, \mathrm{pCO}_{2} 85$ $\mathrm{mmHg}, \mathrm{pO}_{2} 115 \mathrm{mmHg}, \mathrm{HCO}_{3}-29.6 \mathrm{mmol} / \mathrm{L}$.

Decision was made to initiate V-V ECMO for enhanced ventilation and carbon dioxide removal. This was performed on hospital day 6 via bi-femoral venous cannulation; right femoral to right atrium 25 cannula and left femoral cannula to inferior vena cava 23 cannula. Following the establishment of ECMO his blood gasses quickly improved. Values at 120 minutes after initiation of ECMO were: $\mathrm{pH} 7.33, \mathrm{pCO}_{2}$ $40 \mathrm{mmHg}, \mathrm{pO}_{2} 62 \mathrm{mmHg}, \mathrm{HCO}_{3}-21.1 \mathrm{mmol} / \mathrm{L}$. Ventilation was maintained on conventional mechanical mode, with RR of 10, TV of $250 \mathrm{ml}, \mathrm{FiO} 240 \%$, and PEEP of $15 \mathrm{mmHg}$. Rate of ECMO sweep gas flow was initiated at $8 \mathrm{~L} / \mathrm{min}$ and slowly decreased to $3 \mathrm{~L} / \mathrm{min}$ over the next 5 days. He was on continuous nebulized albuterol and Solumedrol $60 \mathrm{mg}$ q6 hours, which was tapered down every 3 days. V-V ECMO was discontinued after 9 days of support and patient was extubated within 24 hours of ECMO cessation. His hospital course was complicated by acute kidney injury which did not require renal replacement therapy. He was discharged initially to a skilled nursing facility and then to home.

At 9 month follow up patient was doing well. He reported using his rescue inhaler 2-3 times per day and was tapering his prednisone from $20 \mathrm{mg} /$ day to $10 \mathrm{mg} /$ day.

\section{Discussion}

Patients with status asthmaticus who have progressive hypercapnia and or hypoxemia often require positive pressure ventilation, but status asthmaticus patients are usually already hyperinflated and have extremely high levels of airway pressure, which increases their risk of ventilator barotrauma and is associated with substantial mortality [2]. ECMO has traditionally been used in infants and children with acute respiratory distress syndrome due to reversible pulmonary disease and as cardiac assistance in patients with circulatory failure [3]. In 1981, Kolobow published the first paper on extracorporeal carbon dioxide removal [4]. However, to date, ECMO is rarely used for the treatment of refractory status asthmaticus in adults. In a 2009 retrospective cohort registry review of the international Extracorporeal Life Support Organization Registry, among 1,257patients treated with ECMO, only 24 (2\%) were asthmatics. Yet, survival to discharge was much higher for the asthmatic group (83\%) as compared to non-asthmatics (50.8\%), even after adjustment for confounders [5].

Presently there are no evidence-based guidelines for initiating ECMO for status asthmaticus. Much of the evidence in support of its use in status asthmaticus is based on case reports with the reported indications in this group ranging from cardiovascular compromise, cardiac arrest, hypoxemia and shock, severe hypercapnia and acidosis, to dynamic hyperinflation $[2,6,7]$.

Based on the results of their own experience with hypercapneic respiratory failure in three patients in status asthmaticus, Kukita et al. suggested a simple algorithm for initiation of ECMO: $\mathrm{pH}$ less than 7.2, $\mathrm{PaCO}_{2}$ greater than $100 \mathrm{~mm} \mathrm{Hg}$, or life threatening conditions of hypoxemia, hypotension, or barotrauma in spite of optimization of ventilatory support [8]. Our patient fit these criteria. He had acute severe asthma, which did not improve despite maximum medical management and ventilator support. He continued to deteriorate and developed hypotension, hypercapnia and severe respiratory acidosis but returned to normal respiratory function within nine days after initiation of ECMO.

\section{Conclusion}

Our case report illustrates the effective use of ECMO in the face of impending cardiorespiratory collapse in a patient with severe respiratory failure due to refractory status asthmaticus.

\section{СПИСОК ЛИТЕРАТУРЫ/REFERENCES}

1. Krishnan V., Diette G.B., Rand C.S., Bilderback A.L., Merriman B., Hansel N.H., Krishnan J.A. Mortality in patients hospitalized for asthma exacerbations in the United States. Am J RespirCrit Care Med. 2006;174(6):633-638.

2. Brenner B., Corbridge T., Kazzi A. Intubation and mechanical ventilation of the asthmatic patient in respiratory failure. Proceedings of the American Thoracic Society. 2009;6(4):371-379.

3. Makdisi G., Wang I. Extra corporeal membrane oxygenation (ECMO) review of a lifesaving technology. J Thorac Dis. 2015;7(7):Е 166-E176.

4. Kolobow T., Gattinoni L., Tomlinson T.,White D., Pierce J., Iapichino G.The carbon dioxide membrane lung (CDML): a new concept. Trans Am SocArtif Intern Organs. 1977;23:17-21.
5. Mikkelsen M.E., Woo Y.J., Sager J.S., Fuchs B.D., Christie J.D. Outcomes using extracorporeal life support for adult respiratory failure due to status asthmaticus. ASAIO J. 2009;55(1):47-52.

6. Jung C., LautenA., Pfeifer R., Bahrmann P., Figulla HR, Ferrari M. Pumpless extracorporeal lung assist for the treatment of severe, refractory status asthmaticus. J Asthma. 2011;48: 111-113

7. Lobas S., Carey M. Rescue of acute refractory hypercapnia and acidosis secondary to life-threatening asthma with extracorporeal carbon dioxide removal (ECCO2R). The Intensive Care Society. 2011;12(2):140-143.

8. Kukita I., Okamoto K., Sato T.Shibata Y., Taki K., Kurose M. et al: Emergency extracorporeal life support for patients with near-fatal status asthmaticus. Am J Emer Med. 1997;15:566-569.

\section{Для корреспонденции:}

Harveen K. Lamba

Address: 11100, Euclid Avenue, Cleveland OH 44106,USA

Tel.+7(216)844-4004,e-mail: hkl12@case.edu
Conflictof interest:

The authors have no financial disclosures or conflicts of interest. Funding: The study did not have sponsorship. 